${ }^{0}$ Entomologica Fennica. 14 February 1997

\title{
Pheromonal and enzyme genetic characteristics of the Bombus lucorum species complex in northern Europe
}

\author{
Pekka Pamilo, Jan Tengö, Pierre Rasmont, Kari Pirhonen, Antti Pekkarinen \& Erkki Kaarnama
}

Pamilo, P., Tengö, J., Rasmont, P., Pirhonen, K., Pekkarinen, A. \& Kaarnama, E. 1997: Pheromonal and enzyme genetic characteristics of the Bombus lucorum species complex in northern Europe. — Entomol. Fennica 7: 187-194.

Spatial and temporal distribution of the species in the Bombus lucorum species complex, B. lucorum (L.), B. cryptarum (Fabricius) and B. magnus Vogt, were studied in Finland. Morphological distinction between the species is not as clear as in Central Europe, but $B$. lucorum can be distinguished from the other two with the help of enzyme genetic markers. $B$. lucorum is the most common of the three species in most of Finland, and B. cryptarum is abundant in the southwestern coastal area and in northern Lapland. B. magnus was only rarely found among the spring queens in southwestern Finland, and its range possibly restricts to southern and central parts of Finland. A comparison of the chemical composition of the male labial glands and enzyme genotypes shows that males produce species-specific marking pheromones.

Pekka Pamilo, Department of Genetics, Uppsala University, Box 7003, S-750 07 Uppsala, Sweden

Jan Tengö, Ecological Research Station of Uppsala University, Ölands Skogsby 6280, S-386 93 Färjestaden, Sweden

Pierre Rasmont, Laboratoire de Zoologie, Université de Mons, Avenue Maistriau, B-7000 Mons, Belgium

Kari Pirhonen, Simolankatu 9, FIN-33270 Tampere, Finland

Antti Pekkarinen, Department of Ecology and Systematics, Box 17, FIN00014 Helsinki University, Finland

Erkki Kaarnama, Pohjoiskaari 6 A 16, FIN-00200 Helsinki, Finland

Received 1 October 1995, accepted 30 June 1996

\section{Introduction}

The males of the bumble bee Bombus lucorum show extensive colour variation (e.g. Pekkarinen 1979), and this variation has been shown to be associated with the chemical composition of marking pheromones produced by the labial glands (Bergström et al. 1973). The pheromonal studies revealed two distinct types of males, one representing the "blonde" and the other one the "dark" form. Later, Bergström et al. (1980) regarded these forms as two sibling species on the basis of their pheromonal differences. Further genetic studies based on enzyme electrophoresis have proved the existence of at least two separate species in the B. lucorum complex (Scholl \& Obrecht 1983, Pamilo et al. 1984). Three enzyme genes have been found to separate the taxa from each other (Scholl et al. 1990), and there is a clear correlation between the electrophoretic types and male colour, 


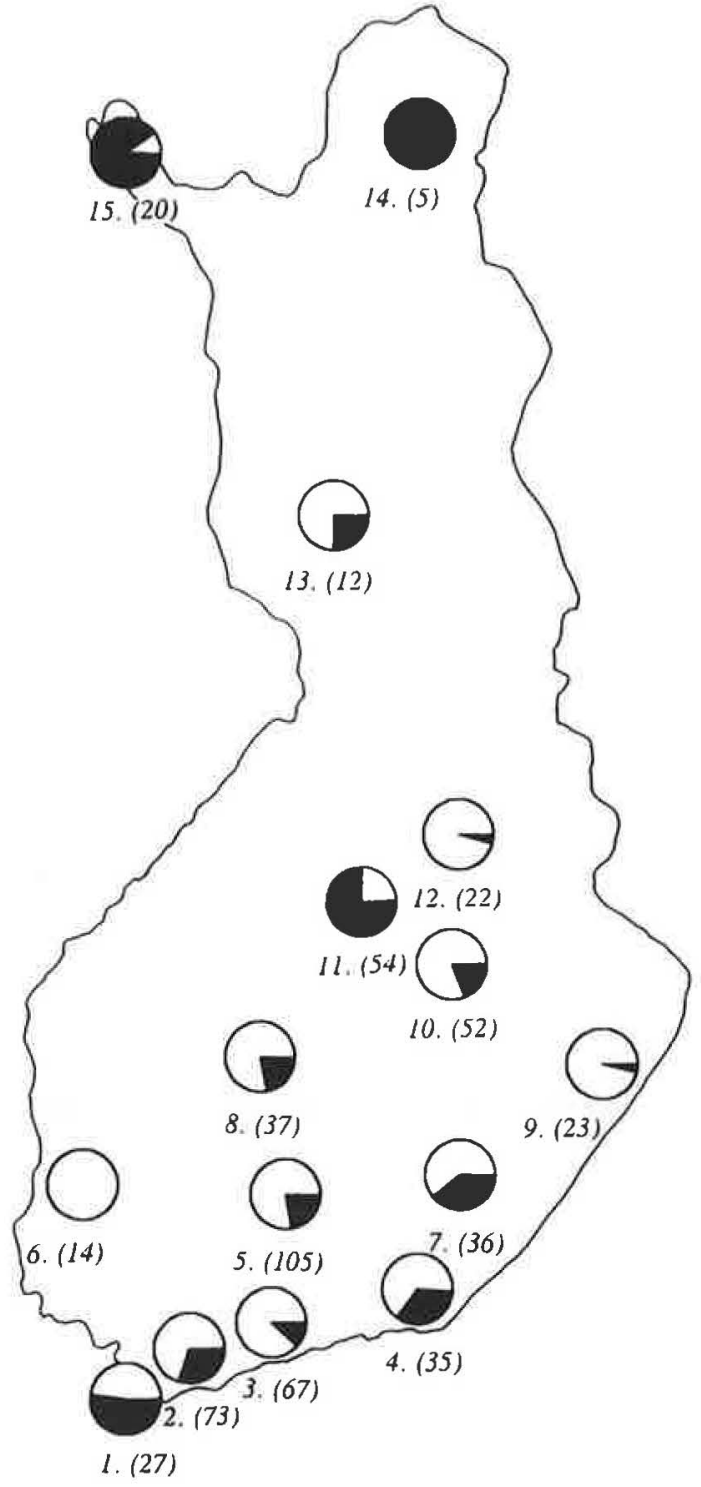

Fig. 1. The occurrence of the two electrophoretic types in Finland. The light sector represents the proportion of $B$. lucorum, and the dark sector stands for $B$. cryptarum and $B$. magnus. The sample sizes are given in parentheses, and the sampling localities are: 1. Hanko, 2. Inkoo and Mustio, 3. Helsinki, 4. Hamina, 5. Hämeenlinna and Lammi, 6. Pori, 7. Mäntyharju, Jaala, Mikkeli and Juva, 8. Keuruu, 9. Tohmajärvi and Uukuniemi, 10. Kuopio, 11. Vieremä, 12. Kajaani, 13. Rovaniemi, 14. Ivalo, and 15. Enontekiö (Karesuanto and Kilpisjärvi).

although there seems to be colour variation within the taxa (Pamilo et al. 1984).
Simultaneously with the electrophoretic studies, De Jonghe and Rasmont approached the taxonomy of the B. lucorum species complex using morphometry and crossing experiments (De Jonghe 1982, De Jonghe \& Rasmont 1983). These, in addition to biogeographical and ecological evidence, led Rasmont $(1981,1984)$ to suggest that there are in fact three closely related species: $B$. lucorum (L.), B. cryptarum (Fabricius) and B. magnus Vogt. Morphological criteria for identifying the species were first given for females (Rasmont 1984) and a little later also for males (Rasmont et al. 1986). Comparisons with the enzyme electrophoretic results showed that one of the electrophoretic types represents $B$. lucorum while the other two species have identical allozyme profiles (Obrecht \& Scholl 1984, Scholl et al. 1990).

The lectotype of Apis terrestris Linnaeus, 1758 designated by Day (1979) has been identified as conspecific with B. cryptarum (Fabricius, 1775) (Rasmont 1988: 52). For the sake of stability in nomenclature, a proposal was made to the International Commission on Zoological Nomenclature (ICZN) (Löken et al. 1994), which affirmed the proposal (ICZN 1996). Thus, the present nomenclature follows that used by Rasmont (1984).

Our aim has been to combine the pheromonal and enzyme genetic studies and to examine the male pheromonal variation within and between the species and the geographical and seasonal distribution of the species in northern Europe.

\section{Material and methods}

Samples for this study were collected in Finland during 1985-1989. Three hundred and seventy-five workers or males were collected from several localities during the summers of 1985 and 1986 in order to clarify the geographical distribution of the species. Combined with our earlier data (Pamilo et al. 1984), the samples come from 15 localities (Fig. 1) and consist of 582 individuals. An additional 28 males were sampled for pheromonal analyses at the Tvärminne Zoological Station in Hanko (Locality 1 in Fig. 1) in September 1986. One hundred and fourty-four overwintered queens were also collected in Hanko in the springs of 1986 and 1987 (May and early June) for a phenological study. Three queens collected in Hanko in 1989 
were set to produce small colonies in nest boxes. All individuals collected in the field, or reared in nest boxes, were frozen for later laboratory studies.

Enzyme electrophoresis was done from flight muscles. A small piece of muscle was homogenized in ca. $50 \mu \mathrm{l}$ distilled water and the samples were then applied to starch gels. We stained two enzymes that were found to separate species in earlier studies, phosphoglucomutase (PGM) and esterase (EST) (Scholl \& Obrecht 1983, Pamilo et al. 1984). We used a tris-citrate EDTA buffer of $\mathrm{pH} 7.1$ (tray buffer $135 \mathrm{mM}$ for Tris, gel buffer diluted 1:16). A fluorescent staining was used for EST.

The overwintered queens were examined morphologically. The species B. lucorum and B. cryptarum, the two most common species in our samples, were identified using the following criteria (see Rasmont 1984 for details): 1) form of labrum (B. lucorum: large lamella somewhat folded, large labral furrow with flattened tubercles; $B$. cryptarum: narrow lamella not folded, narrow labral furrow, raised tubercles); 2) cuticle in the middle of the second gastral tergite (B. lucorum: surface not very shagreened, punctuations narrow and oblique; $B$. cryptarum: surface clearly shagreened, punctuations very large, deep and nearly vertical); 3) collar (B. lucorum: collar not extending below tegulae on episternum and without black hairs; $B$. cryptarum: collar extending below tegulae on dorsal episternum often with an S-shaped pattern with black hairs); and 4) ocellar field (B. lucorum: few large punctuations not deeply impressed along the margins of the compound eyes; $B$. cryptarum: large, dense and deep punctuations). A labrum index (Character 1 above), given as a ratio of the width of the frontal furrow to the basal width, was measured for each queen. Rasmont (1984) has shown this index to be on average 0.29 in B. cryptarum, 0.38 in B. lucorum and 0.41 in B. magnus.

The labial glands of frozen males were dissected and extracted in pentane for gas chromatographic analyses of volatiles. The samples were run on a HP 5880 gas chromatograph, equipped with an integrator (HP 5880 GC Terminal). The separations were carried out on a $30-\mathrm{m}$ fused silica capillary column $(0.22 \mathrm{~mm}$ i.d.) coated with $\mathrm{Su}-$ perox FA under program from $50-220^{\circ} \mathrm{C}$ at a rate of $4^{\circ} \mathrm{C} / \mathrm{min}$. The peaks of the chromatograms were identified based on the respective retention times
(Rt). The same males were also used for enzyme electrophoretic studies. We did not identify the species of the males morphologically.

\section{Results}

\subsection{Geographical distribution}

Our electrophoretic results reveal the same two genetic forms detected earlier. One form has been identified as Bombus lucorum and the other one includes both $B$. cryptarum and B. magnus. The latter two species cannot be separated using the enzymes we have studied. Combined with our earlier observations (Pamilo et al. 1984), the two genetic forms are found throughout Finland, $B$. lucorum being the dominant species with a couple of exceptions (Fig. 1). We found B. lucorum neither at Ivalo (Locality 14) in eastern Lapland nor at Karesuanto (included in Locality 15) in western Lapland. These sample sizes were small, and $B$. lucorum was found previously at Kilpisjärvi (Locality 15), the northernmost part of western Lapland, as well as on the Atlantic coast further northwest from Kilpisjärvi (Pamilo et al. 1984). In the coastal area in the southwestern tip of Finland (Hanko, Locality 1), the two electrophoretic types are about equally common. Similar frequencies have been observed in different years, and they can be considered stable. We have also one sample from central Finland (Vieremä, Locality 11 ), where the frequency of $B$. lucorum was only $25 \%$. The sample included 54 workers but it probably represents a smaller number of nests. However, the individuals were collected from several separate fields and the frequencies were similar in different fields. Records about specimens with largely yellow-haired dorsal episternum indicate that the range of $B$. magnus is restricted to southern and central Finland.

\subsection{Phenology}

The frequency of $B$. lucorum queens decreased in Hanko with the progression of spring (Table 1). Early May, the frequency of $B$. lucorum among the queens was $73 \%$ but decreased to $51 \%$ in early June. The difference between the samples in 1987 was significant $\left(\mathrm{X}^{2}=12.1, \mathrm{df}=3,0.01>\mathrm{P}>0.001\right)$. 


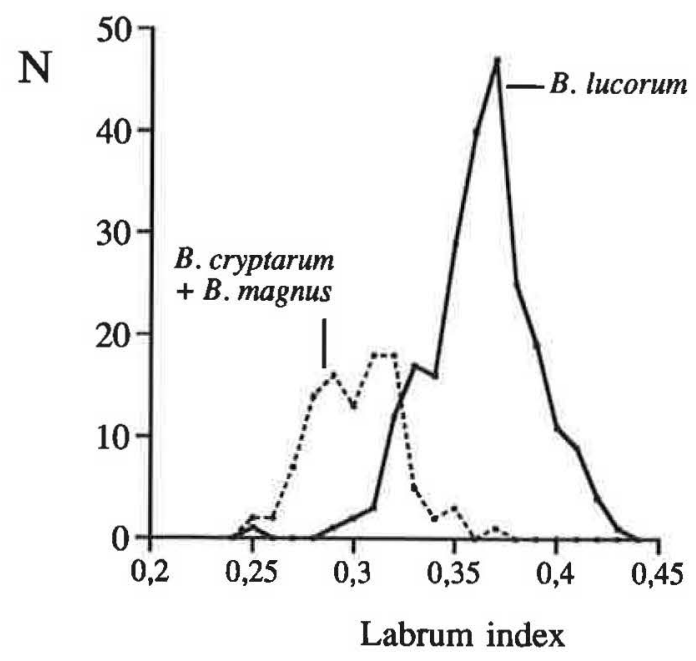

Fig. 2. Distribution of the labrum index in overwintered queens separately for $B$. lucorum (solid line) and combined for $B$. cryptarum and $B$. magnus (broken line). The labrum index is calculated as the ratio of the width of the frontal furrow to basal width.

\subsection{Morphology}

The distributions of the labrum index of $B$. lucorum and B. cryptarum/magnus (Fig. 2) showed an overlap and suggest that the queens in the latter group were mainly $B$. cryptarum. A closer morphological examination of the latter group, using other characters as well (see Rasmont 1984), suggested that a small proportion of these belonged to B. magnus. The individuals that could be identified with a high certainty included four queens of $B$. magnus and 32 of B. cryptarum.

Table 1. Numbers of overwintered queens captured in Hanko in the springs of 1986 and 1987.

\begin{tabular}{lcc}
\hline Date & B. lucorum & B. cryptarum/magnus \\
\hline 1986 & & \\
5 May & 4 & 10 \\
23 May & 23 & 9 \\
12 June & 11 & 8 \\
1987 & & \\
9 May & 115 & 42 \\
19 May & 51 & 18 \\
27 May & 7 & 4 \\
4 June & 33 & 32 \\
\hline
\end{tabular}

One of the three queens that produced a laboratory colony, was identified as $B$. magnus. Yellow hairs of the collar covered about half of her episternum dorsally, the radial length of the forewing (RL of Rasmont 1984) was $4.72 \mathrm{~mm}$, and the labrum index was 0.33 . The queen and her progeny of 20 workers were of the electrophoretic form expected in B. magnus, and all of them had a similar collar, yellow hairs covering about half of the episternum. The two other queens were electrophoretically of the $B$. lucorum form, and their labrum indices were 0.39 and 0.38 . One of the latter colonies produced eight workers and two males, whereas the other produced only two workers. The colour of hairs of the two males was quite similar with the "normal" $B$. lucorum male according to Rasmont et al. (1986: fig. 3) or "medium light" according to Pekkarinen (1979: fig. 6 ), and the queens and workers had no yellow hairs on the episternum.

The morphological examination also showed that the separation of the species, particularly between $B$. lucorum and $B$. cryptarum was not as clear as in the material from central Europe. Particularly the form of the labrum seemed to be more variable in northern than in southern and central Europe. The punctuations in the middle of the second tergite were well typified, providing a good morphological criterion for separating $B$. lucorum from the other two species. A large majority of the Finnish B. cryptarum had a characteristic black $\mathrm{S}$-shaped pattern at the sides of the collar.

\subsection{Male pheromones}

Twenty-eight males collected in autumn 1986 included $22 \mathrm{~B}$. lucorum and six others, based on electrophoretic separation. The quantity of the labial gland contents varied greatly and the number of peaks in the gas chromatograms reflected this variation; some individuals had a small amount of very few substances. The number of peaks that constituted over $2 \%$ of the gland contents in any individual was 28 , and the number constituting at least $5 \%$ was 20 . Ethyl tetradecenoate and 1 -hexadecanol that were characteristic main compounds for the "blonde" form reported by Bergström et al. (1973) gave in our study Rt's of 41.3 and 49.3, respectively (Fig. 3). These Rt values were repre- 
Bombus lucorum

B.cryptarum/magnus

$\begin{array}{lllllllllllllllll}1 & 2 & 3 & 4 & 5 & 6 & 7 & 8 & 9 & 101112131415161718192021 & 22 & 232425262728\end{array}$

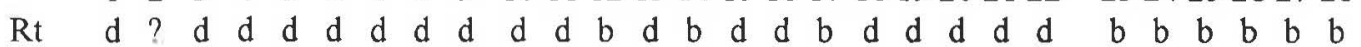

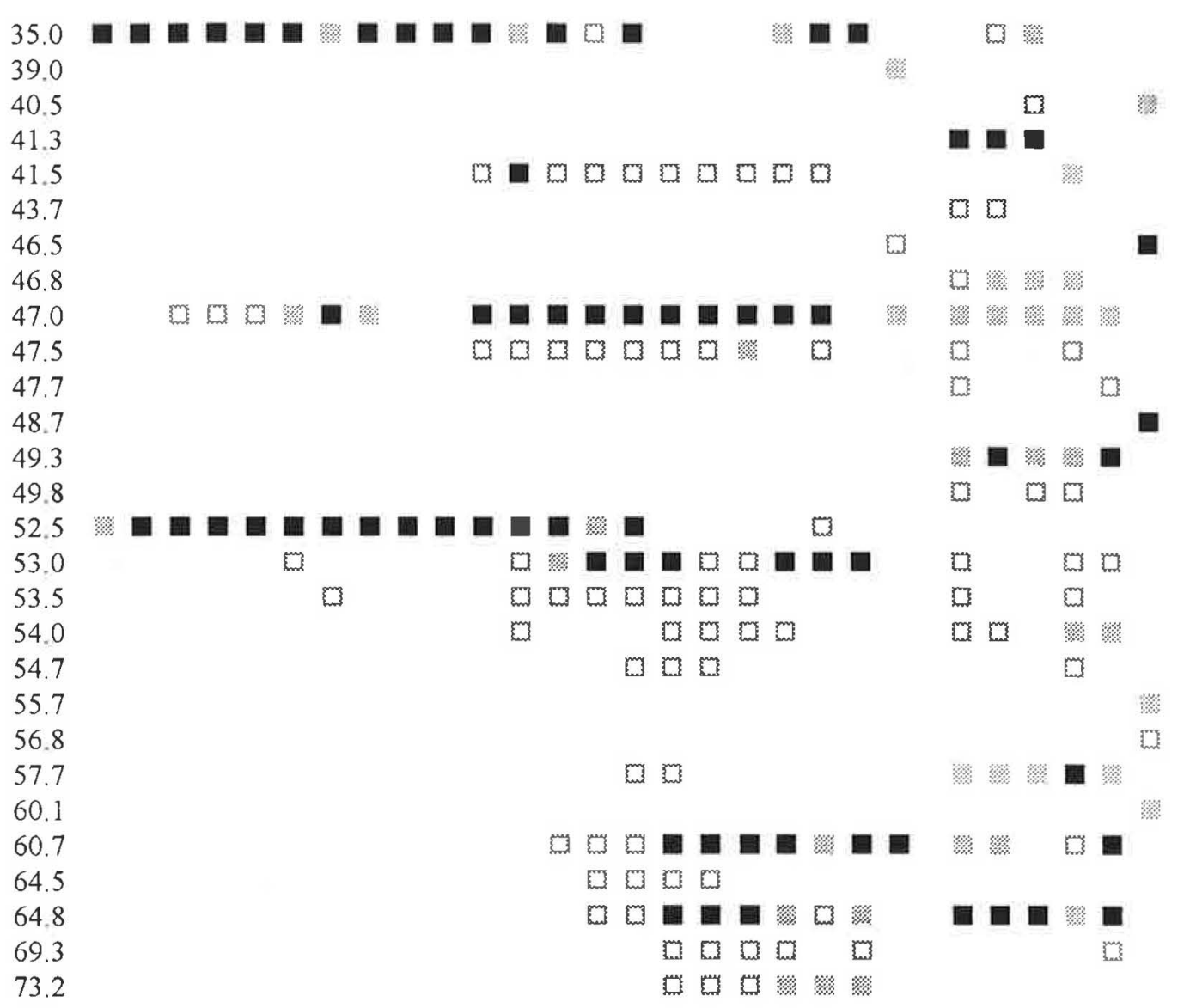

Fig. 3. The major compounds in the labial gland secretions of 28 males (each represented by a column). The proportions of the compounds in the total mixture are indicated by the squares as follows: white 2-5\%, grey 5$10 \%$, and black $>10 \%$. The colour form of each male is indicated under the specimen number $(d=d a r k, b=$ blonde). Rt is the retention time in gas chromatography.

sented by major peaks in the analyses of males with the $B$. cryptarum/magnus electrophoretic type. These peaks were missing in the $B$. lucorum specimens, an absence that could be correlated with the "dark" form of Bergström et al. (1973). The B. lucorum males had one major peak at a $\mathrm{Rt}$ of 35.0 , which corresponded to the retention time of ethyl dodecanoate (Fig. 3).
We estimated the similarities of the compound profiles by using a Euclidean distance of square root transformed proportions. We used this transformation because otherwise the very common compounds would have entirely determined the similarities. The distance matrix was then used to cluster the individuals with a single-link clustering. The resulting dendrogram (Fig. 4) had two 


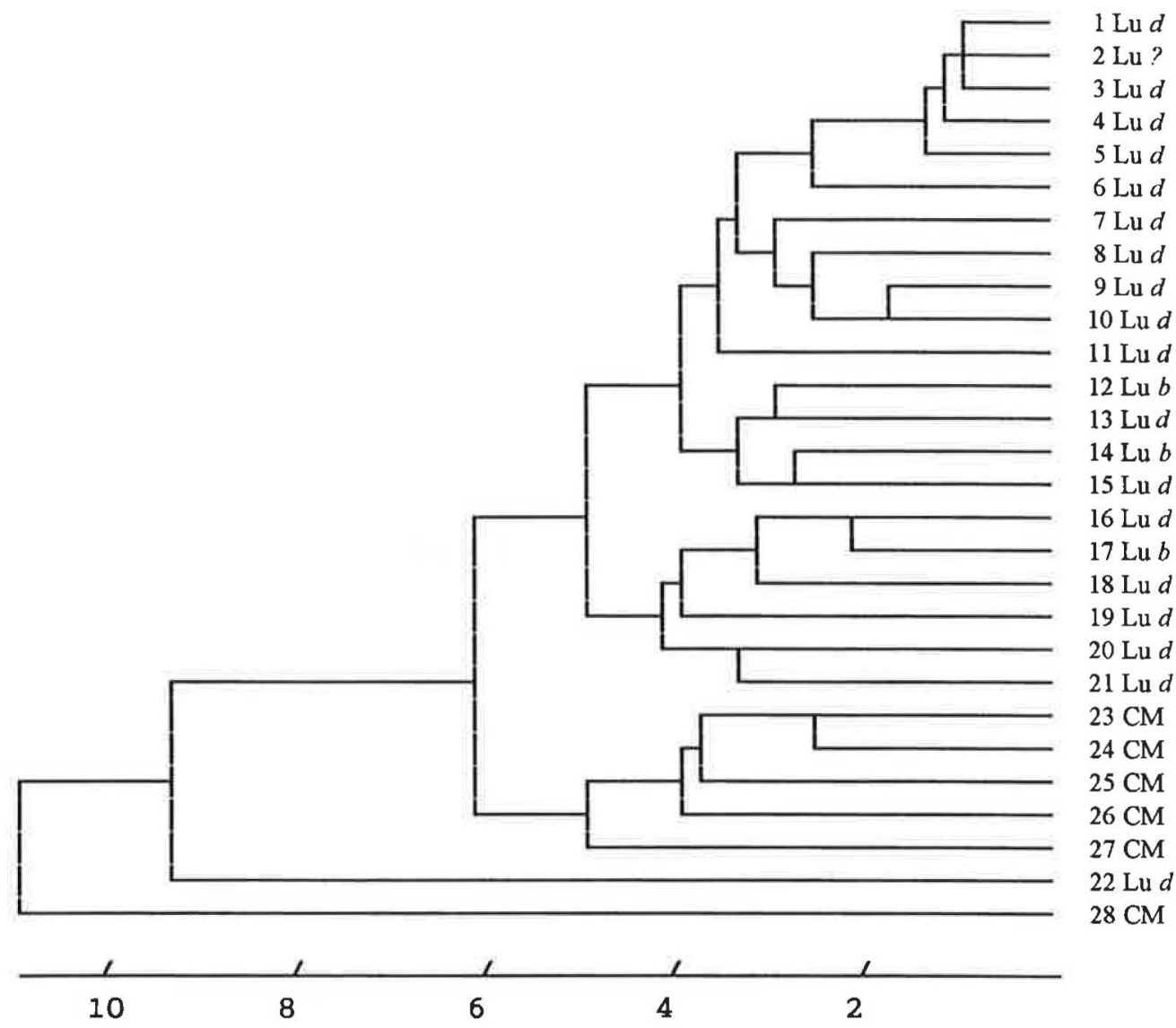

\section{Difference}

Fig. 4. Single-linkage clustering of the pheromonal similarities of the 28 males studied. The species ( $L u=$ $B$. lucorum, $\mathrm{CM}=B$. cryptarum or $B$. magnus) were determined by the enzyme electrophoretic markers. The numbers of the specimens are the same as used in Fig. 3 , and the colour morphs are indicated in $B$. lucorum as $\mathrm{b}=$ blonde and $\mathrm{d}=$ dark.

main clusters, one included $B$. lucorum and the other had B. cryptarum and/or B. magnus. In addition, there were two outliers, one $B$. lucorum and the other either $B$. cryptarum or $B$. magnus. The major division within $B$. lucorum (excluding the outlier \#22) was associated with the presence or absence of a major peak with $\mathrm{Rt}=52.5$ and of peaks with Rt $>60$ (Fig. 3).

\section{Discussion}

All three species, B. lucorum, B. cryptarum and B. magnus occur in northern Europe. In most parts of Finland, B. lucorum is the most abundant spe- cies but is either absent or rare in parts of northern Lapland. Along the Baltic coast in southwestern Finland, B. cryptarum can be as equally abundant as $B$. lucorum, and it is reasonable to assume that the environmental gradient from the mainland to the archipelago is in many aspects similar to that with altitude. Scholl and Obrecht (1983) and Rasmont (1988) found that B. cryptarum increases in frequency with altitude in central and southern Europe. Interestingly, the opposite was observed in Poland, where B. cryptarum is clearly less abundant than B. lucorum (Banaszak \& Rasmont 1994).

The queens from Hanko suggest that $B$. magnus is a rare species. Pekkarinen (1979) doubted 
the species status of $B$. magnus and suggested that this form represents the upper fraction of $B$. lucorum size distribution, and he demonstrated that the differences in metric characters on the head (Löken 1973) are due to allometry. It is now clear that $B$. magnus is different from B. lucorum, but it would be important to get also genetic confirmation for the distinction between $B$. cryptarum and $B$. magnus. The separation between them has been described both on a morphological basis (Rasmont 1984) and in crossing experiments (De Jonghe \& Rasmont 1983). The queens in our material, however, showed less clear morphological separation than found in Central Europe. For example, the labrum index in the queens identified as $B$. magnus was smaller than in B. lucorum, unlike in Central Europe.

The most reliable characters for distinguishing $B$. lucorum and $B$. cryptarum proved to be the form of labrum and the punctuation of the second tergite (Characters 1 and 2 in Material and methods). Rasmont (1984) described several morphological types within B. cryptarum at a subspecific level. Most of the Finnish samples (ca. 80\%) would, in this classification, fit ssp. reinigianus that otherwise occurs mainly in the mountainous regions in Central Europe (Rasmont 1984). The remaining individuals resembled morphologically the type ssp. cryptarum.

The distinction between the pheromone profiles in "blonde" and "dark" males, found by Bergström et al. (1973), was here clearly associated not only with colour variation but also with species-specific enzyme gene differences. There existed also interesting pheromonal variation within both enzyme genetic types, but the dark males belonging to $B$. lucorum did not show any deviant pheromonal patterns within that species. Pheromonal variation within the species most likely was caused by differences in age and the physiological condition of males. They were collected in September, after the main reproductive activity. The pheromones are used for marking flight routes (Svensson 1979) and this is likely to alter the proportions of the compounds remaining in the glands. There was one outlier in both electrophoretic types (Fig. 3). It is premature to suggest that they have any taxonomic significance.

The data on ecological differences between the species are scarce. It would be interesting to have information on the tongue lengths and actual flower usage patterns that affect resource competition. Our observations suggested a phenological difference between $B$. lucorum and $B$. cryptarum queens in spring. The queens of $B$. lucorum seemed to become active earlier. Whether the increase in the frequency of $B$. cryptarum was due to later activity of overwintering queens or to immigration from other localities is not known. Some bumble bee species have extensive spring migrations along the southern coast of Finland. These include the $B$. lucorum species complex (Mikkola 1978 ) but it is not clear whether both $B$. lucorum and $B$. cryptarum have similar tendencies to migrate. The enzyme genetic type including both $B$. cryptarum and B. magnus was common both in the Baltic archipelago and near the Arctic Ocean in northern Lapland. Whether this distribution represented a single species with particular environmental adaptations in these areas, or consisted of the different distribution patterns of two species, remains to be clarified.

Acknowledgements. The electrophoretic analyses were done in the laboratory of the Department of Genetics, University of Helsinki. We thank K. Vainio for her help with the analyses, Wittko Francke for his advice in the interpretation of the GC-results, and Rohert Paxton for constructive criticism of the manuscript. The study has been supported by the Natural Sciences Research Councils of Finland and Sweden.

\section{References}

Banaszak, J. \& Rasmont, P. 1994: Occurrence and distribution of the subgenus Bombus Latreille sensu stricto in Poland (Hymenoptera, Apoidea). - Polskie Pismo Entomol. 63: 337-356.

Bergström, G., Kullenberg, B. \& Ställberg-Stenhagen, S. 1973: Studies on natural odoriferous compounds. VII. Recognition of two forms of Bombus lucorum L. (Hymenoptera, Apidae) by analysis of the volatile marking secretion from individual males. --Chemica Scripta 4: 174-182.

Bergström, G., Svensson, B. G., Appelgren, M. \& Groth, I. 1980: Complexity of bumble bee marking pheromones: biochemical, ecological and systematical interpretations. - In: Howse, P. E. \& Clement, J.-L. (eds.), Biosystematics of social insects: 175-182. Academic Press, New York. 346 pp.

Day, M. C. 1979: The species of Hymenoptera described by Linnaeus in the genera Sphex, Chrysis, Vespa, Apis and Mutilla. - Biol. J. Linn. Soc. 12: 45-84.

De Jonghe, R. 1982: Copulations interspécifiques en capti- 
vité d'espèces du genre Bombus Latreille (sensu stricto) (Hymenoptera, Apidae, Bombinae). — Bull. Ann. Soc. R. Entomol. Belg. 118: 171-175.

De Jonghe, R. \& Rasmont, P. 1983: Kreuzungsexperiment mit Hummeln des Genus Bombus Latreille sensu stricto (Hymenoptera, Apidae). — Phegea 11: 7-10.

International Commission on Zoological Nomenclature 1996: Opinion 1828. Apis terrestris Linnaeus, 1758, A. muscorum Linnaeus, 1758 and A. lucorum Linnaeus, 1761 (currently Bombus terrestris, B. muscorum and B. lucorum) and Bombus humilis Illiger, 1806 (Insecta, Hymenoptera): specific names conserved, and neotypes designated for B. terrestris and B. muscorum. - Bull. Zool. Nomenclature 53: 64-65.

Löken, A. 1973: Studies on Scandinavian bumble bees (Hymenoptera, Apidae). — NorskEntomol. Tidskr. 20: 1-218.

Löken, A., Pekkarinen, A. \& Rasmont, P. 1994: Apis terrestris Linnaeus, 1758, A. muscorum Linnaeus, 1758 and A. Lucorum Linnaeus, 1761 (currently Bombus terrestris, B. muscorum and B. lucorum) and Bombus humilis Illiger, 1806 (Insecta, Hymenoptera): proposed conservation of usage of the specific names. - Bull. Zool. Nomenclature 51: 232-236.

Mikkola, K. 1978: Spring migrations of wasps and bumble bees on the southern coast of Finland (Hymenoptera, Vespidae and Apidae). - Ann. Entomol. Fenn. 44: 10-26.

Obrecht, E. \& Scholl, A. 1984: Bombus lucorum auct., ein Artenkomplex - enzymelektrophoretische Befunde (Hymenoptera, Bombidae). - Verh. Dtsch. Zool. Ges. 77: 266.

Pamilo, P., Varvio-Aho, S. \& Pekkarinen, A. 1984: Genelic variation in bumblebees (Bombus, Psithyrus) and putative sibling species of Bombus lucorum. - Hereditas 101: 245-251.
Pekkarinen, A. 1979: Morphometric, colour and enzyme variation in bumblebees (Hymenoptera, Apidae, Bombus) in Fennoscandia and Denmark. - Acta Zool. Fenn. 158: $1-60$.

Rasmont, P. 1981: Redescription d'une espèce méconnue de bourdon d'Europe: Bombus lucocryptarum Ball, 1914 n. status (Hymenoptera, Apidae, Bombinae). Bull. Ann. Soc. R. Entomol. Belg. 117: 149-154.

Rasmont, P. 1983: Catalogue commenté de la région Ouestpalearctique (Hymenoptera, Apoidea, Apidae). Notes Faun. Gembloux 7: 1-7.

Rasmont, P. 1984: Les bourdons du genre Bombus Latreille sensu stricto en Europe occidentale et centrale. Spixiana 7: 136-160.

Rasmont, P. 1988: Monographie écoloque et zoogéographique des bourdons de France et de Belgique (Hymenoptera, Apidae, Bembinae). — Ph.D.-thesis, Fac. Sciences Agron, l'Etat Gembloux. 309 pp. + LXii.

Rasmont, P., Scholl, A., de Jonghe, R., Obrecht, E. \& Adamski, A. 1986: Identité et variabilité des mâles de bourdons du genre Bombus Latreille sensu stricto en Europe occidentale et centrale (Hymenoptera, Apidae, Bombinae). -- Rev. Suisse Zool. 93: 661-682.

Scholl, A. \& Obrecht, E. 1983: Enzymelektrophoretische Untersuchungen zur Artabgrenzung im Bombus lucorum-Komplex (Apidae, Bombini), - Apidologie 14: $65-78$.

Scholl, A., Obrecht, E. \& Owen, R. E. 1990: The genetic relationship between Bombus moderatus Cresson and the Bombus lucorum auct. species complex (Hymenoptera: Apidae). — Can. J. Zool. 68: 2264-2268.

Svensson, B. G. 1979: Patrolling behaviour of bumble bee males (Hym., Apidae) in a subalpine/alpine area, Swedish Lapland. - Zoon 7: 67-94. 